University of Nebraska - Lincoln

DigitalCommons@University of Nebraska - Lincoln

Patterns of maternal yolk hormones in eastern screech owl eggs (Megascops asio)

D. Caldwell Hahn

USGS, chahn@usgs.gov

Follow this and additional works at: https://digitalcommons.unl.edu/usgsstaffpub

Hahn, D. Caldwell, "Patterns of maternal yolk hormones in eastern screech owl eggs (Megascops asio)" (2011). USGS Staff -- Published Research. 543.

https://digitalcommons.unl.edu/usgsstaffpub/543

This Article is brought to you for free and open access by the US Geological Survey at DigitalCommons@University of Nebraska - Lincoln. It has been accepted for inclusion in USGS Staff -- Published Research by an authorized administrator of DigitalCommons@University of Nebraska - Lincoln. 


\title{
Patterns of maternal yolk hormones in eastern screech owl eggs (Megascops asio)
}

\author{
D. Caldwell Hahn* \\ USGS-Patuxent Wildlife Research Center, 12100 Beech Forest Road, Laurel, MD 20708, USA
}

\section{A R T I C L E I N F O}

\section{Article history:}

Received 14 October 2010

Revised 26 March 2011

Accepted 4 April 2011

Available online 12 April 2011

\section{Keywords:}

Steroid hormones

Yolk

Androgens

Corticosterone

Estradiol

Egg laying order

Owls

Maternal effects

Sibling feeding hierarchy

\begin{abstract}
A B S T R A C T
Owl clutches typically hatch asynchronously, and brood size hierarchies develop. In this study, we describe intra-clutch variation of testosterone, androstenedione, estradiol, and corticosterone in Eastern screech owl egg yolks. In order to assess whether these hormones may have originated in the follicle, we also characterize variation of testosterone, androstenedione, and corticosterone within the exterior, intermediate, and interior regions of the yolk. Concentrations of testosterone and androstenedione were distributed relatively evenly across egg lay order with the exception of first-laid eggs that had significantly lower concentrations of both androgens than eggs later in the laying sequence. Corticosterone and estradiol did not vary with laying order. Our results suggest that when food is abundant, yolk hormones are deposited in patterns that minimize sibling differences except to reduce dominance by the first-hatching chick. Testosterone and androstenedione concentrations varied throughout the yolk, while corticosterone was evenly distributed throughout the yolk. This supports a follicular origin for both yolk androgens, and an adrenal origin for yolk corticosterone.
\end{abstract}

Published by Elsevier Inc.

\section{Introduction}

Owls were the classic example that David Lack used to explain how female birds adjust brood size to the available food supply. Lack suggested that a sibling hierarchy based on age forms through asynchronous hatching, and this allows older and larger nestlings to monopolize a majority of the food resources. If food becomes limited, younger nestlings perish and minimal energy is wasted. Lack's insight stimulated considerable interest in the role female birds play in adjusting the onset of incubation, the resulting disparities created among nestlings, and the adaptive function of sibling asymmetries in a wide range of species $[21,38,48,60,66-68]$. In 1993, Schwabl's [53] discovery that female birds deposit yolk steroids in differential concentrations within their clutches widened the focus of maternal effects beyond asynchronous hatching to include the role that egg hormones play in sibling competition and development.

Several steroid hormones have been identified in avian eggs, including testosterone, 5 $\alpha$-dihydrotestosterone, estradiol [53], androstenedione [53], progesterone [31], and corticosterone [53]. Exposure to high concentrations of yolk androgens has generally been found to be correlated with increased growth and survivorship [19], increased boldness [9,61] and alertness [11], and more vigorous begging [53]. However, negative effects of yolk androgens

\footnotetext{
* Fax: +1 7035329465.

E-mail address: chahn@usgs.gov
}

on growth and survival have also been described [40,43,57]. Elevated yolk corticosterone has often been found to be associated with negative effects on offspring quality, including reduced growth $[14,23,24,51]$, increased activity of the hypothalamicpituitary-adrenal axis as adults [23], slower plumage development [51], and depressed immunity [50], although exposure to elevated yolk corticosterone was also found to dampen the response to stress in fledglings [35]. Concentrations of corticosterone may adaptively match maternal quality with offspring demand $[33,35]$, and elevated embryonic exposure to corticosterone may induce phenotypes that increase survival in low-quality environments [7]. Estradiol is typically present in yolk at much lower concentrations in comparison to yolk androgens [6], but exposure during development may also alter offspring phenotype [64].

Since Schwabl's [53] discovery, work on within-clutch patterns of yolk steroids has found different within-clutch patterns in different species, and it has been suggested that the variable patterns reflect different life-history strategies [34,58]. In some species, androgen concentrations increase $[15,30,47,54]$ or corticosterone concentrations decrease [34] across the laying order. Both these patterns could benefit later-hatching nestlings by counteracting the formation of a sibling hierarchy. In other species, androgen concentrations decrease [55] or corticosterone concentrations increase $[27,36]$ across the laying order, both of which could handicap later-hatching nestlings and reinforce the effects of hatching asynchrony. Because yolk estradiol concentrations are often undetectable [19] or do not vary with laying order [37], estradiol is not 
thought to play a role in mediating asynchronous hatching. However, in zebra finches (Taeniopygia guttata), within-clutch variation of yolk estradiol concentrations has been described [69].

In this study, we investigated within-clutch patterns of four yolk steroids-testosterone, androstenedione, corticosterone, and estradiol-in clutches of Eastern screech owl (Megascops asio) eggs. Few raptors have been examined to determine the pattern of yolk androgen concentrations, and this is the first study of a nocturnal raptor. Most owls are heavily dependent for food on rodents and other small mammals $[25,29,59]$, and these groups are characterized by extreme population fluctuations $[12,13]$. Consequently owls adjust their brood size to extreme changes in food supply $[13,25,59]$. We hypothesized that screech owls might utilize yolk hormones to reinforce the age-based sibling hierarchy, thus employing a physiological mechanism to make the hierarchy more effective. Specifically, we predicted that yolk androgen concentrations would decrease across the laying order in Eastern screech owl, because this pattern would support a sibling feeding hierarchy, providing older chicks with the benefits associated with higher androgen concentrations noted above. We hypothesized that corticosterone concentrations would increase across the laying order because this pattern would handicap younger chicks and reinforce a sibling hierarchy. Because yolk estradiol concentrations have not been well characterized, we also measured estradiol in the yolks of screech owl eggs.

Yolk androgens have most frequently been reported to increase across egg lay order $[17,19]$, but we based our prediction that they would decrease on the life history traits of owls [25]. The extreme fluctuations of owls' food supply appear to impose strong selection on the effectiveness of the sibling feeding hierarchy, and we hypothesized that a physiological mechanism like decreasing yolk androgens could contribute to sibling asymmetries and enhance the effectiveness of the sibling feeding hierarchy. In addition, owls do not show sibling aggression or declining egg size with lay order [25], traits that contribute to brood reduction in some other asynchronously-hatching species $[10,41]$. In owls the clutch size is typically large (4-5) and the nestling period is long (28-30 days), conditions under which a sibling feeding hierarchy is particularly effective as a food distribution system [25].

Since Lack's work, asynchronous hatching has been found to be a widespread trait, but it is often accompanied by other traits that facilitate brood reduction $[10,41]$. In boobies and eagles, asynchronous hatching is accompanied by aggressive behavior in nestlings, and obligate siblicide effects brood reduction [45,62,65]. In gulls, including kittiwakes, asynchronous hatching is accompanied by decreasing egg size in later-laid eggs, and brood reduction is accomplished by a sibling feeding hierarchy reinforced by lower survival of chicks from smaller eggs [4,21]. Asynchronous hatching may also be present without brood reduction. In some species, primarily songbirds, asynchronous hatching is hypothesized to reduce predation rather than to reduce the brood size [8], because it shortens the time that eggs and young are in the nest and allows older chicks to fledge early if necessary. This strategy is consistent with the "hatching asynchrony adjustment hypothesis" [19], in which increasing yolk androgen concentrations partially compensate for the delayed hatching of later-laid eggs. Consequently, differences in life history strategy are considered important to understand the variability among species in yolk hormone patterns [34].

We also investigated the distribution of testosterone, androstenedione, and corticosterone within the yolks of screech owl eggs. Differences in concentrations within yolk layers provide evidence to the origin of yolk steroids and may have important consequences for developing embryos. Few studies have found a correlation between yolk androgen concentrations and blood concentrations in females $[39,44,48,70]$, so it has been suggested that yolk androgens originate in the follicle [18]. In contrast, yolk corticosterone has been shown to positively correlate with blood concentrations in females, and it has been suggested that corticosterone originates in the adrenal gland [32]. We expected testosterone and androstenedione to decrease from interior to the exterior of the yolk, because this pattern reflects androgen production by the follicle during egg formation. In the domestic hen, testosterone production increases early in the period of yolk production and then remains relatively constant before dropping off sharply during the last $24 \mathrm{~h}$ of yolk deposition [2]. In contrast, corticosterone was expected to be evenly distributed throughout the yolk.

\section{Materials and methods}

\subsection{Study species}

The Eastern screech owl is a small owl (males are typically $160 \mathrm{~g}$, females $200 \mathrm{~g}$ ) that has a broad ecological niche and a large geographic range. Screech owl clutches contain between 2 and 8 eggs, although 4-6 eggs is typical. The first 2 or 3 eggs are typically laid 1 day apart, with increasing intervals thereafter [16,63]. Eggs are incubated for approximately 28 days, and hatch asynchronously over 3 or more days (personal observation). The young fledge at 28-30 days of age [16]. The owls used in this study were members of a captive breeding colony at USGS-Patuxent Wildlife Research Center, Laurel, MD. Owls were housed in outdoor flight cages $(12 \times 3 \mathrm{~m})$ that contained nest-boxes, and breeding pairs were kept together year-round. Pairs were provided two mice per bird daily, as well as Nebraska Brand Bird of Prey Diet (Central Nebraska Packing, Inc., North Platte, NE), and pairs were provided two additional mice per day for each nestling as soon as it hatched.

\subsection{Egg collection}

In 2006 and 2007, nests were monitored closely during egg-laying. Eggs were collected within $3 \mathrm{~h}$ of laying and replaced with artificial eggs. In 2006, 57 eggs were collected from 15 clutches for a study of within-clutch variation in maternal hormones. In 2007, 28 eggs from 10 different clutches were collected for a study of variation in maternal hormone concentration in different regions of the yolk. Eggs from both years were stored at $-70^{\circ} \mathrm{C}$ until analysis.

\subsection{Yolk hormone analysis}

For all samples, the yolk and albumen were separated. In 2006, yolks were weighed to the nearest $0.01 \mathrm{~g}$ on a digital scale, and whole yolks were homogenized with an equal volume of phospho-saline buffer (PBS). Hormones were extracted using absolute ethanol according to the procedure used by Kozlowski et al. [26]. Briefly, yolk samples were homogenized and incubated at $37^{\circ} \mathrm{C}$ for $1 \mathrm{~h}$. After incubation, $500 \mu \mathrm{L}$ of absolute ethanol was added to $500 \mu \mathrm{L}$ of the yolk/PBS mixture. Upon adding ethanol, the samples were immediately homogenized again, and allowed to incubate at room temperate for $10 \mathrm{~min}$. Samples were then spun in a centrifuge for $10 \mathrm{~min}$ at $12,282 \mathrm{~g}$. The supernatant was retained and assayed for testosterone, androstenedione, corticosterone and estradiol.

In 2007, we followed the methods of Lipar et al. [31] to assess hormone distribution throughout the yolk. Frozen yolks were dissected with a scalpel blade, and samples of similar mass were taken from the interior, intermediate, and exterior layers of the yolk. Sample masses were recorded immediately upon dissection and ranged from 0.08 to $0.21 \mathrm{~g}$. The largest difference in mass between samples from the same eggs was $0.05 \mathrm{~g}$. Since hormone 
concentrations are expressed as nanograms per gram of yolk, variation in the sample masses did not contribute to error in the measurement of hormone concentrations. Individual samples were homogenized in $1.5 \mathrm{ml}$ microcentrifuge tubes with $200 \mu \mathrm{L}$ of PBS. Hormones were extracted using absolute ethanol as described above, and supernatant was assayed for testosterone, androstenedione, and corticosterone.

All samples were analyzed using radioimmunoassay (RIA) in the Endocrinology Lab at the Saint Louis Zoo. In preparation for assay, ethanol extracts were thawed and spun in a centrifuge at $4500 \mathrm{~g}$ for 10 min to remove any remaining lipids. Hormone concentrations were measured using commercially available RIA kits: testosterone (Coat-A-Count $\odot$ Testosterone 125I Kit, Diagnostic Products Corporation, Los Angeles, CA), androstenedione (Coat-A-Count $\odot$ Direct Androstenedione 125I Kit, Diagnostic Products Corporation, Los Angeles, CA), estradiol (Double Antibody Estradiol 125I Kit, Diagnostic Products Corporation, Los Angeles, CA), and corticosterone (Double Antibody Corticosterone Kit, ICN MP Biomedicals). In our assays, the upper and lower detection limits were as follows: testosterone: $0.05-40 \mathrm{ng} / \mathrm{ml}$; androstenedione: $0.10-10 \mathrm{ng} / \mathrm{ml}$; corticosterone: $0.13-5 \mathrm{ng} / \mathrm{ml}$; estradiol: $0.005-0.50 \mathrm{ng} / \mathrm{ml}$. All kits have highly specific antibodies and low cross-reactivities with other steroids. The following cross-reactivity data were supplied by the manufacturer.

The testosterone antibody cross-reacts as follows: $5 \beta$-androstan-3 $\alpha, 17 \beta$-diol: $0.4 \%$; androstenedione: $0.5 \%$; $5 \beta$-androstan- $3 \beta$, 17 $\beta$-diol: $0.2 \%$; $5 \alpha$-dihydrotestosterone: $3.3 \%$; $5(10)$-estren$17 \alpha$-ethinyl-17 $\beta$-ol-3-one: $0.2 \%$; 4 -estren-17 $\alpha$-methyl-17 $\beta$-ol-3one: $1.1 \%$; 4-estren-17-ol-3-one: 20\%; 19-nortestosterone: $20 \%$; ethisterone: $0.7 \%$; 19-hydroxyandrostenedione: $2.0 \%$; 11-ketotestosterone: $16 \%$; methyltestosterone: $1.7 \%$; norethindrone: $0.1 \%$; $11 \beta$-hydroxyyestosterone: $0.8 \%$; and triamincinolone: $0.2 \%$. Crossreactivities for all other compounds are below $0.1 \%$.

The androstenedione antibody cross-reacts as follows: androsterone: $0.14 \%$; DHEA: $0.16 \%$; progesterone: $0.16 \%$; spironolactone: $0.11 \%$; $5 \alpha$-dihydrotestosterone: $0.21 \%$; and testosterone: $1.49 \%$. Cross-reactivities for all other compounds are below $0.1 \%$.

The estradiol antibody cross-reacts as follows: $d$-equilenin: 4.2\%; $17 \beta$-estradiol-3 $\beta$-D-glucuronide: $6.0 \%$; $\beta$-estradiol 17 -propionate: $0.43 \% ; 1,3,5(10)$-estratrien-17 $\alpha$-ethinyl-3,17 $\beta$-diol 3-methyl ether: $0.87 \%$; 1,3,5(10)-estratrien-17 $\alpha$-methyl-3,17 $\beta$-diol 3-methyl ether: $3.5 \%$; 4 -estren-17 $\alpha$-ethinyl-17 $\beta$-ol-3-one: $0.14 \%$; 4 -estren$17 \beta$-ol-3-one: $1.75 \%$; estriol: $0.24 \%$; estrone: $12.5 \%$; estrone- $\beta$-Dglucuronide: $1.6 \%$. Cross-reactivities for all other compounds are below $0.1 \%$.

The corticosterone antibody cross-reacts as follows: desoxycorticosterone: $0.34 \%$; testosterone: $0.10 \%$; progesterone: $0.02 \%$; pregnenolone: <0.01\%; and $17 \alpha$-hydroxyprogesterone: $<0.01 \%$.

Assays were run according to kit directions, with the exception that the kit standards for testosterone, androstenedione, and estradiol, which are supplied in human serum, were replaced by standards obtained from Sigma Chemical (Saint Louis, MO), and diluted in $10 \%$ steroid-free calf serum. In all assays, standard diluent was added to extracted yolk samples, and steroid-free yolk extract was added to standards and quality controls. Calf serum and yolk extract were stripped of steroids using dextran-coated charcoal (DCC \#6241, Sigma Chemical, Saint Louis, MO) prior to use.

Eggs from the same clutch, and yolk sections from the same egg, were measured in the same assay, and all samples were measured in duplicate. Mean \pm SEM intra-assay variation of duplicate samples was $4.9 \pm 0.4$ for testosterone, $9.6 \pm 0.9$ for androstenedione, $5.6 \pm 0.5$ for estradiol, and $4.5 \pm 0.6$ for corticosterone. Inter-assay variation of quality controls was $3.5 \pm 2.5$ for testosterone, $4.3 \pm 1.9$ for androstenedione, $7.5 \pm 1.7$ for corticosterone, and $8.6 \pm 4.77$ for estradiol.

\subsection{Assay validation}

All assays were tested for linearity by diluting four samples that contained high concentrations of hormone by $1 / 2,1 / 4$, and $1 / 8$ with steroid-free yolk extract. Serial dilutions gave calculated observed/expected values of $91.22 \pm 2.21 \%$ (mean \pm SE) of expected values for testosterone, $102.45 \pm 2.92 \%$ of expected values for androstenedione, $94.32 \pm 5.1 \%$ of expected values for corticosterone, and $98.54 \pm 3.1 \%$ of expected values for estradiol. We assessed the accuracy of the assay by adding a known amount of hormone to four yolk extracts containing low values of hormone. Addition of known amounts of each hormone at three dosage levels resulted in recovery of $101.68 \pm 4.14 \%$ of added testosterone, $90.89 \pm 4.53 \%$ of added androstenedione, $96.52 \pm 6.41 \%$ of added estradiol, and $92.71 \pm 3.94 \%$ of added corticosterone.

\subsection{Statistical methods}

Hormone concentrations were analyzed using mixed model analysis of covariance for a within-clutch data set examining egg lay order and a within-egg data set to examine yolk layer [52]. The model fit the repeated measures within-clutch with the structure compound symmetry. Two possible random models were examined and the better random model was selected based on goodness of fit statistics. The two choices were a homogeneous variance model fitting a single residual variance or a heterogeneous variance model fitting a separate residual variance for each egg number. The residuals for all hormones were examined and in most case there was some skewing to the right. However, the degree of skewing was not considered serious given the large number of replicates for each egg lay order and for each yolk layer.

When the analysis resulted in a significant egg lay order effect or significant yolk layer effect, Tukey-Kramer HSD was used to identify differences between pairs of means for egg lay order or for egg yolk layer. For the within-clutch data analyses, the fixed portion of the model included egg lay order, while yolk mass as a covariate. The random effects were female and the residual variance(s). Only the analysis of androstenedione resulted in a heterogeneous residual variance model. For the within-egg data analyses, the fixed portion of the model included egg yolk layer, while yolk mass was a covariate. The random effects were female, egg lay order and the residual variance(s). Only the analysis of corticosterone resulted in a heterogeneous residual variance model.

\section{Results}

\subsection{Within-clutch variation in yolk hormone concentrations}

The average yolk mass was $4.080 \pm 0.090 \mathrm{~g}$ and ranged from 3.44 to $5.69 \mathrm{~g}$. Yolk mass did not differ in response to egg lay order $\left(F_{3,39}=0.57, P=0.635\right)$. The average concentration of yolk testosterone was $32.3 \pm 2.5 \mathrm{ng} / \mathrm{g}$ and ranged from 10.5 to $75.6 \mathrm{ng} / \mathrm{g}$. The average concentration of yolk androstenedione was $39.6 \pm 4.1 \mathrm{ng} / \mathrm{g}$, and ranged from 11.3 to $105.5 \mathrm{ng} / \mathrm{g}$.

Yolk corticosterone concentrations averaged $2.28 \pm 0.21 \mathrm{ng} / \mathrm{g}$ and ranged from 0.95 to $4.33 \mathrm{ng} / \mathrm{g}$, and yolk estradiol concentrations averaged $4.47 \pm 0.34 \mathrm{ng} / \mathrm{g}$ and ranged from 2.49 to $11.38 \mathrm{ng} / \mathrm{g}$. The concentrations of the four hormones in egg yolk were significantly different $\left(F_{3,46}=137.66 ; \quad P<0.0001\right) \quad$ (Fig. 1$)$. Tukey-Kramer post hoc tests were performed, and all mean differences were significant.

Yolk androgens were distributed relatively evenly across egg lay orders $(P>0.585$ all tests) except for the first eggs, which contained significantly lower concentrations of testosterone as 


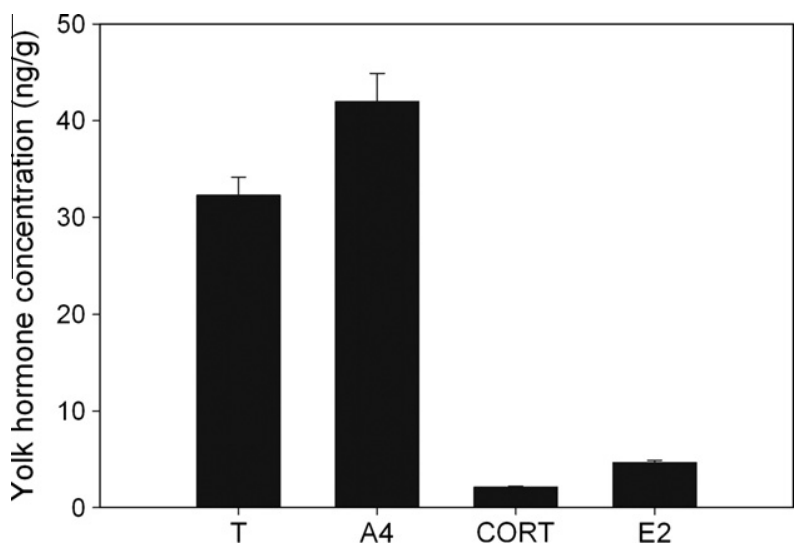

Fig. 1. Mean $( \pm S E)$ yolk steroid concentration in 57 owl eggs from 15 clutches (testosterone: T; androstenedione: A4; corticosterone: CORT; estradiol: E2).

compared to second and third eggs $(P=0.010)$ (egg order effect: $\left.F_{3,40}=5.00, P=0.005\right)$ (Fig. $2 \mathrm{~A}$ ) and androstenedione (egg order effect: $F_{3,23}=14.95, P<0.001$ ) (Fig. $2 B$ ) where first egg concentrations were lower than second-, third-, and fourth-laid eggs $(P<0.001$ for all tests). Testosterone and androstenedione concentrations did not differ between second-, third- and fourth-laid eggs $\left(P>0.148\right.$ for all tests). Yolk corticosterone $\left(F_{3,36}=0.15, P=0.927\right)$

(Fig. 2C) and yolk estradiol concentrations $\left(F_{3,40}=1.65, P=0.193\right)$

(Fig. 2D) did not vary with laying order. Concentrations of testosterone, androstenedione, corticosterone, and estradiol did not vary $(P>0.321$ for all tests) with yolk mass.
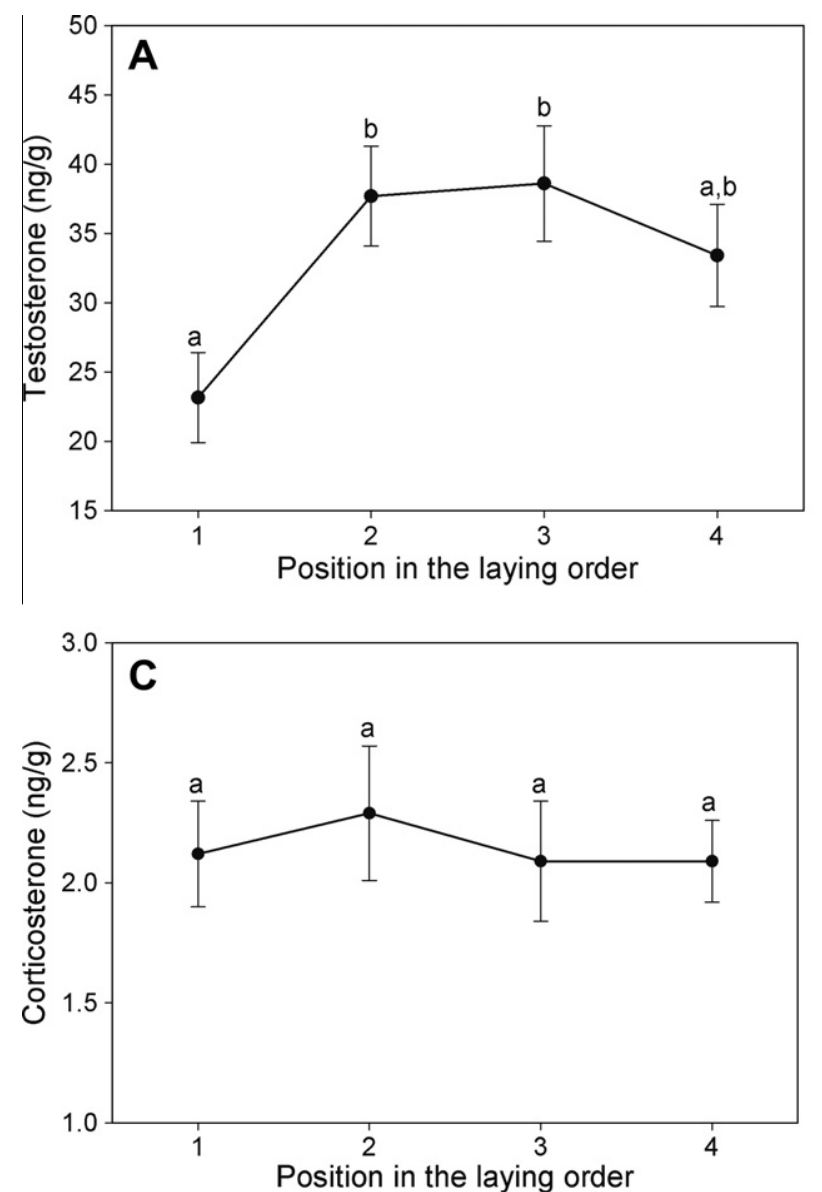

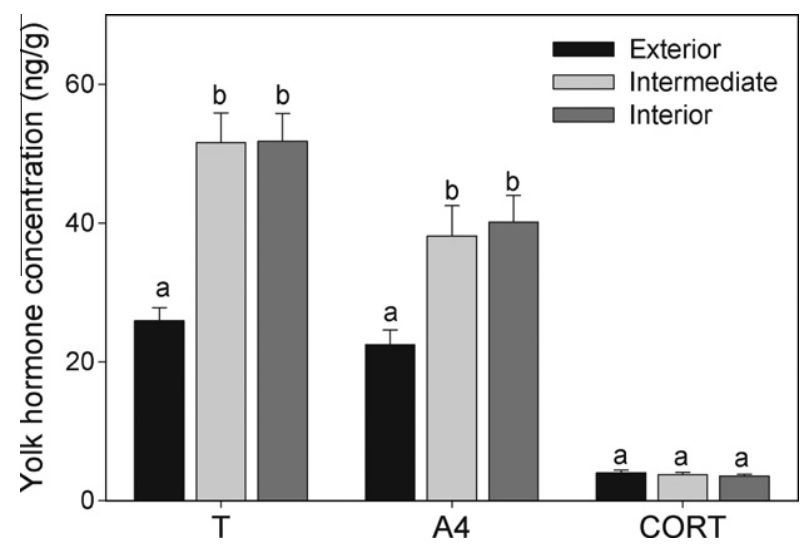

Fig. 3. Mean $( \pm S E)$ yolk steroid concentration in the exterior, intermediate, and interior sections of yolk ( $n=28$ eggs). For each hormone, levels not connected by the same letter $(\mathrm{a}, \mathrm{b}) 600$ are significantly different (testosterone: $\mathrm{T}$; androstenedione: A4; corticosterone: CORT).

\subsection{Variation of hormone concentrations within the yolk}

Average ( \pm SE) testosterone concentration was $25.5 \pm 2.1 \mathrm{ng} / \mathrm{g}$ in the exterior layer of the yolk, $50.9 \pm 3.7 \mathrm{ng} / \mathrm{g}$ in the intermediate layer, and $51.0 \pm 3.6$ in the interior layer (Table 1). Average $( \pm \mathrm{SE}$ ) androstenedione concentration was $22.8 \pm 4.0 \mathrm{ng} / \mathrm{g}$ in the exterior layer of the yolk, $38.9 \pm 4.0 \mathrm{ng} / \mathrm{g}$ in the intermediate layer, and $40.7 \pm 4.0$ in the interior layer. Average ( \pm S.E.) corticosterone concentration was $4.07 \pm 0.38 \mathrm{ng} / \mathrm{g}$ in the exterior layer of the yolk,
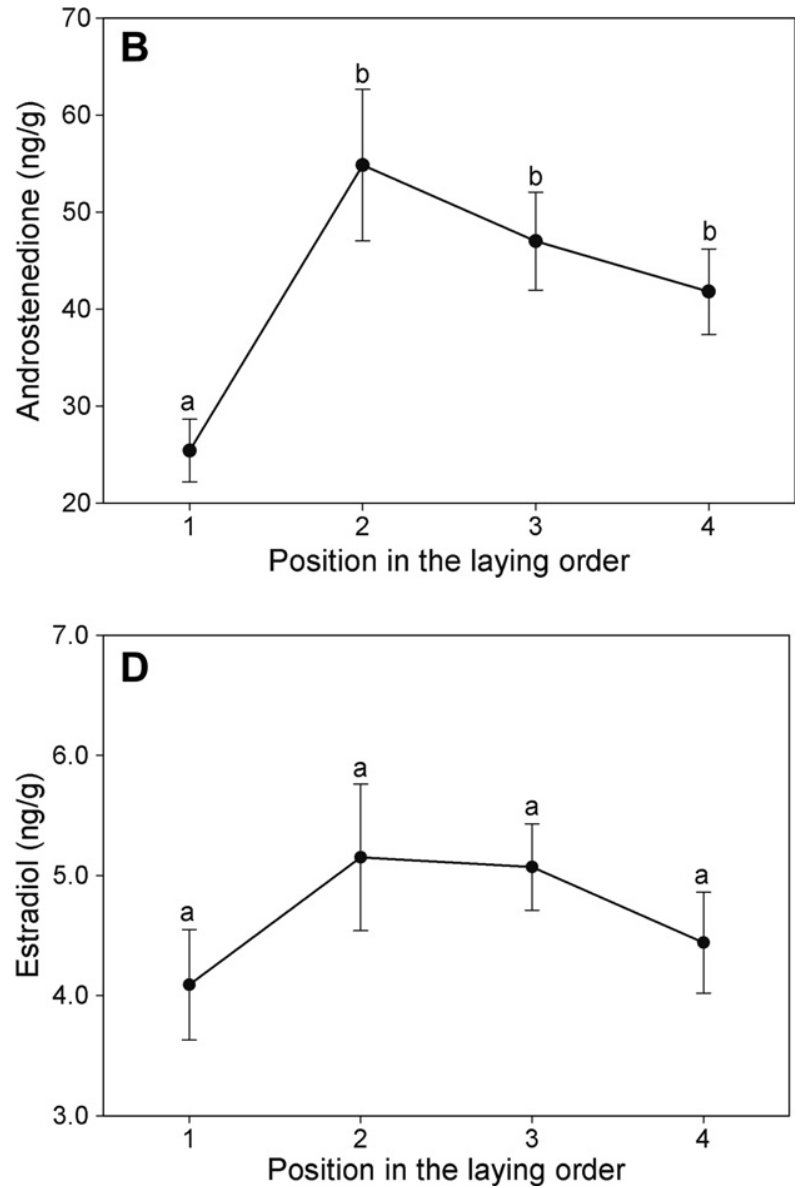

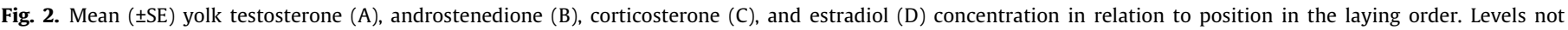
connected by the same letter ( $\mathrm{a}$ and $\mathrm{b}$ ) are significantly different. 
Table 1

Hormone concentrations in different layers of yolk.

\begin{tabular}{llll}
\hline Yolk layer & $\begin{array}{l}\text { Testosterone } \\
(\mathrm{ng} / \mathrm{g})\end{array}$ & $\begin{array}{l}\text { Androstenedione } \\
(\mathrm{ng} / \mathrm{g})\end{array}$ & $\begin{array}{l}\text { Corticosterone } \\
(\mathrm{ng} / \mathrm{g})\end{array}$ \\
\hline Interior & $51.0 \pm 3.6$ & $40.7 \pm 4.0$ & $3.60 \pm 0.32$ \\
Middle & $50.9 \pm 3.7$ & $38.9 \pm 4.0$ & $3.82 \pm 0.32$ \\
Exterior & $25.5 \pm 2.1$ & $22.8 \pm 4.0$ & $4.7 \pm 0.38$ \\
\hline
\end{tabular}

$3.82 \pm 0.32 \mathrm{ng} / \mathrm{g}$ in the intermediate layer, and $3.60 \pm 0.32$ in the interior layer.

Concentrations of both testosterone $\left(F_{2,41}=69.15, P<0.001\right)$ and androstenedione $\left(F_{2,50}=34.68, P<0.001\right)$, but not corticosterone $\left(F_{2,29}=1.65, P=0.210\right)$, differed significantly between different yolk regions (Fig. 3). The exterior yolk layer contained significantly lower concentrations of testosterone and androstenedione than both the intermediate $(P<0.001)$ and interior $(P<0.001)$ regions, whereas the intermediate and interior regions contained equal concentrations of both testosterone $(P=0.999)$ and androstenedione $(P=0.721)$. Corticosterone concentrations were evenly distributed throughout the yolk $(P>0.222$ for all tests). Yolk testosterone $(P=0.445)$, androstenedione $(P=0.438)$, and corticosterone $(P=0.06)$ were not significantly related to yolk mass.

\section{Discussion}

\subsection{Within-clutch pattern}

\subsubsection{Yolk androgens and corticosterone}

Comparative studies have found a variety of within-clutch patterns of yolk androgen and corticosterone concentrations. In some species, yolk androgen concentrations vary across the laying order and mediate sibling hierarchies $[30,47,54]$, while in other species, variation in yolk corticosterone concentrations appears to be important for mediating sibling interactions $[27,34,36]$. Whether both steroids vary in concert or independently to mediate sibling interactions for most species is unknown. The reasons why females birds often deposit different concentrations of yolk hormones in sequential eggs of a clutch is still not well understood, but measurements of yolk hormones in previously unexamined species contribute to our appreciation of the variations in the withinclutch patterns. Life history strategy differences are increasingly considered key to interpreting the effects of yolk hormones on embryos, nestlings, and parental reproductive success [34].

Owls frequently experience brood reduction because of extreme fluctuations in their food supply $[13,25,28,59]$. We hypothesized that a within-clutch pattern of decreasing androgens and increasing corticosterone would constitute a physiological mechanism that reinforced the age-based sibling feeding hierarchy. However, we found a relatively even distribution of both yolk androgens within the clutch, with only the first egg showing lower concentrations. This same pattern was reported for another raptor, American kestrel [57], a pattern that appears likely to minimize sibling differences and have little effect on the existing sibling hierarchy other than to reduce dominance associated with the first-hatching nestling. We found an even distribution of corticosterone within the clutch of screech owl eggs, a pattern that also minimizes differences among siblings and is expected to have little effect on the existing age-based hierarchy. It is notable that the same pattern of even distribution was reported for common eider (Somateria mollissima), a precocial species that does not have sibling competition for parental feeding [34].

The relatively even distribution of yolk hormones that we report here for eastern screech owl may be characteristic of this species when it has a plentiful food supply. The owls in this study were captive, and the food provided is typically sufficient to raise the full brood (Hahn, unpublished data). Future experimental work is necessary to explore the plasticity of the screech owl's yolk hormone deposition in response to food supply. It is possible that female screech owls do not elevate yolk androgens or corticosterone in response to food supply and thus avoid the long-term negative effects that may be associated with these hormones $[19,42]$. Female screech owls may also show other responses to poor food supply. For example, Bunn et al. [5] found that barn owls dramatically adjusted clutch size to changes in abundance of rodents. Another raptor, American kestrel, adjusts hatching asynchrony in relation to food supply, hatching its young more synchronously when food is abundant and more asynchronously when food is limited [67]. Both these adjustments optimize the number of young fledged [68], but comparable data are not available for screech owl.

\subsubsection{Estradiol}

Estradiol was detected in the yolk of Eastern screech owl eggs at a significantly lower concentration than both yolk androgens. Estradiol is typically present in yolk at low concentrations [6]. The low transfer of estradiol may be related to the fact that estradiol plays a major role during sexual differentiation, and this process can be severely affected by even small changes in estradiol concentration [1]. In screech owl clutches, yolk estradiol concentrations did not vary with laying order. Lack of within-clutch variation in estradiol has similarly been reported in a number of species: canaries [56], several species of songbirds, including song sparrow (Melospiza melodia), red-winged blackbird (Agelaius phoeniceus), brown-headed cowbird (Molothus ater), house sparrow (Passer domesticus), Eastern phoebe (Sayornis phoebe), house finch (Carpodacus mexicanus) [22], as well as grackles (Quiscalus quiscula) [3] and Canada geese (Branta canadensis) [37]. Our results, like most previous studies, suggest that yolk estradiol does not enhance the effects of hatching asynchrony.

\subsection{Yolk layer pattern}

Because many studies fail to find a positive correlation between yolk androgen concentrations and concentrations in the serum of laying females [27,44,46,69], it is believed that androgens present in the yolk are follicular in origin [20,31]. In contrast, yolk corticosterone has been shown to positively correlate with blood concentrations in females, and is believed to originate in the adrenal gland [32]. Our results support these studies. Both androgens were differentially distributed throughout the yolk of Eastern screech owl eggs. The exterior layer of the yolk contained significantly less testosterone and androstenedione than the intermediate and interior layer of the yolk, reflecting the pattern of testosterone production by the follicle during egg formation. In the domestic hen, testosterone production increases early in the period of yolk production and then remains relatively constant before dropping off sharply during the last $24 \mathrm{~h}$ of yolk deposition [2]. Yolk corticosterone concentrations were evenly distributed throughout the yolk. This pattern is expected if yolk corticosterone originates from the female's adrenal gland and is transferred to the yolk via the bloodstream.

Differences in androgen concentrations among yolk layers may have important consequences for developing embryos. The utilization of yolk by embryos is accomplished by the formation of the yolk sac, an organ that encapsulates the yolk and is connected to the embryo via a system of vitelline arteries and veins [49]. These blood vessels cover the yolk sac and are responsible for the transport of yolk substances to the circulatory vasculature of the embryo through endocytosis and enzymatic catabolism. Both of these processes occur at the interface of the yolk and the yolk 
sac, which suggests that absorption of the yolk may proceed from the exterior to the interior of the yolk. If true, this would mean embryos are exposed to different concentrations of androgens at different periods of development. However, it is unknown whether variation in steroid hormones among yolk layers persists throughout embryonic development.

\section{Conclusions}

We hypothesized that Eastern screech owl would exhibit within-clutch patterns of decreasing yolk androgens and increasing corticosterone, physiological adjustments that could reinforce the effectiveness of a sibling feeding hierarchy based on age. Because owls are dependent for food on rodents and small mammals whose populations fluctuate dramatically in size [13], owls frequently experience brood reduction when the food supply is poor $[25,28,29]$. We found that both testosterone and androstenedione were deposited relatively evenly among egg lay orders, showing lower concentrations only in the first-laid egg, while corticosterone did not vary with lay order. These patterns minimize differences among siblings and do not appear likely to influence the age-based sibling hierarchy except to reduce dominance associated with the first-hatching chick. The pattern we report may be characteristic of screech owl clutches when food is abundant and the full brood is raised. Estradiol was present in the yolk of screech owl eggs, but at much lower concentrations, and did not vary across the laying order. This suggests that estradiol does not play a role in the sibling hierarchy.

As has been demonstrated in several other species, concentrations of testosterone and androstenedione varied throughout the yolk in a pattern that may parallel the production of androgens by the follicle, supporting a follicular origin for both hormones. Yolk corticosterone was evenly distributed throughout the yolk, suggesting that it originates from the female's adrenal gland is transferred to the yolk via the bloodstream. Further study is needed to determine the whether the within-clutch pattern of yolk androgens differs when food resources are limited.

\section{Acknowledgments}

USGS-Patuxent Wildlife Research Center and Graham W. Smith kindly provided access to the owl colony. USGS-PWRC and Maryland Ornithological Society generously provided research support. Corinne Kozlowski, Saint Louis Zoo Research Department, conducted hormone assays and contributed to literature search. Larry Douglass, Department of Animal Sciences, University of Maryland, carried out statistical analyses. We appreciate Wayne Bauer and Mary Paul for providing care of the owls and Kelly Amy, Chris Gordon, Melody Nevins, and Nathan Rolls for assisting with monitoring egg laying and collecting eggs. John B. French, Barnett Rattner, J.J. Atwood, and two anonymous reviewers provided helpful reviews of the manuscript. Use of trade, product, or firm names does not imply endorsement by the U.S. Government.

\section{References}

[1] E.K. Adkins, Hormonal basis of sexual differentiation in the Japanese quail, Journal of Comparative and Physiological Psychology 89 (1975) 61-71.

[2] J.M. Bahr et al., Steroid concentrations in isolated theca and granulosa layers of preovulatory follicles during the ovulatory cycle of the domestic hen, Biological Reproduction 29 (1983) 326-334.

[3] T.A. Boonstra, M.E. Clark, W.L. Reed, Maternal resource variation across the laying sequence in Canada geese Branta canadensis maxima, Journal of Avian Biology 40 (5) (2009) 520-528.

[4] B.M. Braun, G.L. Hunt, Brood reduction in black-legged kittiwakes, Auk 100 (1983) 469-476.

[5] D.S. Bunn, A.B. Warburton, R.D.S. Wilson, The Barn Owl, T. \& A.D. Poyser, London, 1982.
[6] C. Carere, J. Balthazart, Sexual versus individual differentiation: the controversial role of avian maternal hormones, Trends in Endocrinology and Metabolism 18 (2) (2007) 73-80.

[7] E.H. Chin et al., Juveniles exposed to embryonic corticosterone have enhanced flight performance, Proceedings of the Royal Society of London, Series B: Biological Sciences 276 (1656) (2009) 499-505.

[8] A.B. Clark, D.W. Wilson, Avian breeding adaptations: hatching asynchrony, brood reduction and nest failure, Quarterly Review of Biology 56 (1981) 253277.

[9] J.N. Daisley et al., Enhanced yolk testosterone influences behavioral phenotype independent of sex in Japanese quail chicks Coturnix japonica, Hormones and Behavior 47 (2) (2005) 185-194.

[10] P.R. Ehrlich, D.S. Dobkin, D. Wheye, The Birder's Handbook: A Field Guide to the Natural History of North American Birds, Simon and Schuster, New York, 1988.

[11] C.M. Eising, T.G.G. Groothuis, Yolk androgens and begging behaviour in blackheaded gull chicks: an experimental field study, Animal Behaviour 66 (2003) 1027-1034.

[12] C. Elton, Voles, Mice and Lemmings-Problems in Population Dynamics, Oxford University Press, Oxford, 1942.

[13] C. Elton, Animal Ecology, Methuen \& Co. Ltd., London, 1968.

[14] M.S. Eriksen et al., Prenatal exposure to corticosterone impairs embryonic development and increases fluctuating asymmetry in chickens (Gallus gallus domesticus), British Poultry Science 44 (5) (2003) 690-697.

[15] J. Gasparini et al., Food availability affects the maternal transfer of androgens and antibodies into eggs of a colonial seabird, Journal of Evolutionary Biology 20 (3) (2007) 874-880.

[16] F.R. Gehlbach, The Eastern Screech Owl: Life History, Ecology and Behavior in the Suburbs and Countryside, Texas A\&M University Press, College Station, TX, 1994.

[17] D. Gil, Golden eggs: maternal manipulation of offspring phenotype by egg androgen in birds, Ardeola 50 (2) (2003) 281-294.

[18] T.G. Groothuis, H. Schwabl, Determinants of within- and among-clutch variation in levels of maternal hormones in black-headed gull eggs, Functional Ecology 16 (3) (2002) 281-289.

[19] T.G.G. Groothuis et al., Maternal hormones as a tool to adjust offspring phenotype in avian species, Neuroscience and Biobehavioral Reviews 29 (2) (2005) 329-352.

[20] T.G.G. Groothuis, H. Schwabl, Hormone-mediated maternal effects in birds: mechanisms matter but what do we know of them?, Philosophical Transactions of the Royal Society B: Biological Sciences 363 (1497) (2008) 1647-1661

[21] D.C. Hahn, Asynchronous hatching in the laughing gull-cutting losses and reducing rivalry, Animal Behaviour 29 (1981) 421-427.

[22] D.C. Hahn et al., Inter-species variation in yolk steroid levels and a cowbirdhost comparison, Journal of Avian Biology 36 (1) (2005) 40-46.

[23] L.S. Hayward, J.C. Wingfield, Maternal corticosterone is transferred to avian yolk and may alter offspring growth and adult phenotype, General and Comparative Endocrinology 135 (3) (2004) 365-371.

[24] A.M. Janczak, B.O. Braastad, M. Bakken, Behavioural effects of embryonic exposure to corticosterone in chickens, Applied Animal Behavior Science 96 (2005) 69-82.

[25] P.A. Johnsgard, North American Owls: Biology and Natural History, second ed., Smithsonian Institution Press, Washington, DC, 2002.

[26] C.P. Kozlowski, J.E. Bauman, D.C. Hahn, A simplified method for extracting androgens from avian egg yolks, Zoo Biology 28 (2) (2009) 137-143.

[27] C.P. Kozlowski, R.E. Ricklefs, Egg size and yolk steroids vary across the laying order in cockatiel clutches: a strategy for reinforcing brood hierarchies? General and Comparative Endocrinology 168 (3) (2010) 460-465

[28] D. Lack, The Natural Regulation of Animal Numbers, Oxford University Press, Oxford, 1954.

[29] D. Lack, Population Studies of Birds, Oxford University Press, Oxford, 1966.

[30] J.L. Lipar, E.D. Ketterson, V. Nolan, Intraclutch variation in testosterone content of red-winged blackbird eggs, Auk 116 (1) (1999) 231-235.

[31] J.L. Lipar et al., Egg yolk layers vary in the concentration of steroid hormones in two avian species, General and Comparative Endocrinology 115 (2) (1999) 220-227.

[32] O.P. Love et al., Stress hormones: a link between maternal condition and sexbiased reproductive investment, American Naturalist 166 (6) (2005) 751-766.

[33] O.P. Love et al., Using life-histories to predict and interpret variability in yolk hormones, General and Comparative Endocrinology 163 (2009) 169-174.

[34] O.P. Love et al., Using life-histories to predict and interpret variability in yolk hormones, General and Comparative Endocrinology 163 (1-2) (2009) 169174.

[35] O.P. Love, T.D. Williams, The adaptive value of stress-induced phenotypes: effects of maternally derived corticosterone on sex-biased investment, cost of reproduction, and maternal fitness, American Naturalist 172 (4) (2008) E135E149.

[36] O.P. Love et al., Determinants of within- and among-clutch variation in yolk corticosterone in the European starling, Hormones and Behavior 53 (1) (2008) $104-111$.

[37] J.D. Maddox, R.M. Bowden, P.J. Weatherhead, Yolk testosterone and estradiol variation relative to clutch size, laying order and hatching asynchrony in Common Grackles, Journal of Ornithology 149 (4) (2008) 643-649.

[38] M.J.L. Magrath, L. Brouwer, J. Komdeur, Egg size and laying order in relation to offspring sex in the extreme sexually size dimorphic brown songlark, 
Cinclorhamphus cruralis, Behavioral Ecology and Sociobiology 54 (3) (2003) 240-248.

[39] J. Mazuc et al., Social environment affects female and egg testosterone levels in the house sparrow (Passer domesticus), Ecology Letters 6 (12) (2003) 10841090 .

[40] N.B. Metcalfe, P. Monaghan, Growth versus lifespan: perspectives from evolutionary ecology, Experimental Gerontology 38 (9) (2003) 935-940.

[41] D.W. Mock, G.A. Parker, Siblicide, family conflict and the evolutionary limits of selfishness, Animal Behaviour 56 (1998) 1-10.

[42] W. Mueller et al., Prenatal androgen exposure modulates cellular and humoral immune function of black-headed gull chicks, Proceedings of the Royal Society of London, Series B: Biological Sciences 272 (1575) (2005) 1971-1977.

[43] W. Muller et al., An experimental study on the causes of sex-biased mortality in the black-headed gull-the possible role of testosterone, Journal of Animal Ecology 74 (4) (2005) 735-741.

[44] K.J. Navara et al., Yolk androgens vary inversely to maternal androgens in eastern bluebirds: an experimental study, Functional Ecology 20 (3) (2006) 449-456.

[45] N.J. Nelson, The Sulidae: Gannets and Boobies, Oxford University Press, Oxford, 1978.

[46] K.M. Pilz, H.G. Smith, Egg yolk androgen levels increase with breeding density in the European starling, Sturnus vulgaris, Functional Ecology 18 (1)(2004) 5866.

[47] K.M. Pilz et al., Interfemale variation in egg yolk androgen allocation in the European starling: do high-quality females invest more?, Animal Behaviour 65 (2003) 841-850

[48] C. Rodriguez, K. Johst, J. Bustamante, Parental versus offspring control on food division within the brood: the role of hatching asynchrony, Oikos 117 (5) (2008) 719-728.

[49] V.V. Rol'nik, Bird Embryology Israel Program for Scientific Translations, Jerusalem 1970, Israel Program for Scientific Translations, Jerusalem, 1970.

[50] D. Rubolini et al., Effects of elevated egg corticosterone levels on behavior, growth, and immunity of yellow-legged gull (Larus michahellis) chicks, Hormones and Behavior 47 (5) (2005) 592-605.

[51] N. Saino et al., Stressed mothers lay eggs with high corticosterone levels which produce low-quality offspring, Journal of Experimental Zoology, Part A: Comparative Experimental Biology 303A (11) (2005) 998-1006.

[52] SAS_Institute, SAS Procedures Guide, SAS Institute, Cary, NC, 2003.

[53] H. Schwabl, Yolk is a source of maternal testosterone for developing birds, Proceedings of the National Academy of Sciences of the United States of America 90 (24) (1993) 11446-11450.

[54] H. Schwabl, Yolk is a source of maternal testosterone for developing birds, Proceedings of the National Academy of Sciences of the United States of America 90 (1993) 11446-11450.

[55] H. Schwabl, D.W. Mock, J.A. Gieg, A hormonal mechanism for parental favouritism, Nature 386 (6622) (1997) 231.
[56] K.W. Sockman, H. Schwabl, Daily estradiol and progesterone levels relative to laying and onset of incubation in canaries, General and Comparative Endocrinology 114 (2) (1999) 257-268.

[57] K.W. Sockman, H. Schwabl, Yolk androgens reduce offspring survival, Proceedings of the Royal Society of London, Series B: Biological Sciences 267 (1451) (2000) 1451-1456.

[58] K.W. Sockman, P.J. Sharp, H. Schwabl, Orchestration of avian reproductive effort: an integration of the ultimate and proximate bases for flexibility in clutch size, incubation behaviour, and yolk androgen deposition, Biological Reviews 81 (4) (2006) 629-666.

[59] N.H. Southern, Tawny owls and their prey, Ibis 96 (1954) 384-410.

[60] S.H. Stoleson, S.R. Beissinger, Hatching asynchrony and the onset of incubation in birds, revisited: when is the critical period?, Current Ornithology 12 (1995) $191-270$

[61] R. Strasser, H. Schwabl, Yolk testosterone organizes behavior and male plumage coloration in house sparrows (Passer domesticus), Behavioral Ecology and Sociobiology 56 (5) (2004) 491-497.

[62] E.M. Tarlow, M. Wikelski, D.J. Anderson, Hormonal correlates of siblicide in Galapagos Nazca boobies, Hormones and Behavior 40 (1) (2001) 1420.

[63] L.F. VanCamp, C.J. Henny, The Screech Owl: Its Life History and Population Ecology in Northern Ohio, U.S. Fish and Wildlife Service, North American Fauna, 1975.

[64] N. von Engelhardt et al., Effects of 17-beta-estradiol treatment of female zebra finches on offspring sex ratio and survival, Hormones and Behavior 45 (5) (2004) 306-313.

[65] R.T. Watson et al., Breeding, growth, development, and management of the Madagascar fish-eagle (Haliaeetus vociferoides), Journal of Raptor Research 30 (1) (1996) 21-27.

[66] K.L. Wiebe, G.R. Bortolotti, Energetic efficiency of reproduction-the benefits of asynchronous hatching for American kestrels, Journal of Animal Ecology 63 (3) (1994) 551-560.

[67] K.L. Wiebe, G.R. Bortolotti, Food-supply and hatching spans of birdsenergy constraints or facultative manipulation, Ecology 75 (3) (1994) 813823.

[68] K.L. Wiebe, G.R. Bortolotti, Food-dependent benefits of hatching asynchrony in American kestrels Falco sparverius, Behavioral Ecology and Sociobiology 36 (1) (1995) 49-57.

[69] T.D. Williams et al., Laying-sequence-specific variation in yolk oestrogen levels, and relationship to plasma oestrogen in female zebra finches (Taeniopygia guttata), Proceedings of the Royal Society of London, Series B: Biological Sciences 272 (1559) (2005) 173-177.

[70] T.D. Williams, A.S. Kitaysky, F. Vezina, Individual variation in plasma estradiol17 beta and androgen levels during egg formation in the European starling Sturnus vulgaris: implications for regulation of yolk steroids, General and Comparative Endocrinology 136 (3) (2004) 346-352. 